\title{
Study on the Accurate Measurement and Quantitative Evaluation Methods of Aggregate Surface Roughness
}

\author{
Luoke Li ${ }^{(D)}{ }^{1}$ Meng Guo $\mathbb{D}^{2},{ }^{2}$ and Cong Zeng ${ }^{3}$ \\ ${ }^{1}$ Faculty of Civil Engineering and Mechanics, Kunming University of Science and Technology, Kunming 650500, China \\ ${ }^{2}$ The Key Laboratory of Urban Security and Disaster Engineering of Ministry of Education, Beijing University of Technology, \\ Beijing 100124, China \\ ${ }^{3}$ School of Civil Engineering and Architecture, Northeast Electric Power University, Jilin 132012, China \\ Correspondence should be addressed to Meng Guo; gm@bjut.edu.cn
}

Received 4 November 2020; Revised 15 December 2020; Accepted 28 December 2020; Published 20 January 2021

Academic Editor: Qinglin Guo

Copyright (c) 2021 Luoke Li et al. This is an open access article distributed under the Creative Commons Attribution License, which permits unrestricted use, distribution, and reproduction in any medium, provided the original work is properly cited.

\begin{abstract}
In this work, to quantitatively analyze the roughness of the surfaces of road aggregates, the contact measurement technique and contactless scanning technique were, respectively, used to capture the coordinate data of point clouds on the aggregate surface, which were then used to reconstruct the digital elevation models of aggregate particles. Then, the joint roughness coefficient (JRC) was used as an evaluation index, and the quantitative calculation methods of the two-dimensional (2D) contour line roughness and three-dimensional (3D) contour surface roughness of aggregate particles were, respectively, studied. Finally, the anisotropic characteristics and size effect of the roughness coefficients of aggregates with different lithologies were, respectively, investigated, based on which the practicability of the $3 \mathrm{D}$ roughness coefficient index was proven. The results demonstrate that the roughness of a road aggregate surface can be quantitatively described by the point cloud data. The $2 \mathrm{D}$ roughness of aggregate profile lines exhibits anisotropy, while the 3D roughness of the aggregate contour surface indicates the size effect. The subtle morphological changes of the surface textures of aggregates can be accurately described by the $3 \mathrm{D}$ joint roughness coefficient $\left(J R C^{3 \mathrm{D}}\right)$ calculated by the feature parameter method.
\end{abstract}

\section{Introduction}

Rock aggregates are commonly used raw materials in the field of road engineering, and their surface roughness significantly affects the performance of asphalt mixtures [1]. The rough surface is beneficial to increasing the contact area between the aggregate and asphalt, thereby creating a certain penetration depth of the asphalt, increasing the thickness of the asphalt film, and enhancing the physical adsorption of the two materials on the contact surface [2-6]. Additionally, there are many fine protrusions on the surfaces of aggregates, which is conducive to the formation of the aggregate skeleton structure of the asphalt mixture during the mixing process, thereby endowing asphalt concrete with good shear strength and ultimately improving the rutting resistance of the road surface [7-9].

From the aspect of the collection of aggregate surface morphology data, with the continuous development of measurement technology, a variety of measurement methods have been applied to obtain the characteristic information of the surfaces of rock materials. According to the acquisition method, these methods can be divided into contact contour measurement methods and noncontact optical measurement methods. Additionally, according to the dimension, the data can be divided into two-dimensional (2D) contour line coordinate data and three-dimensional (3D) contour surface coordinate data $[10,11]$. To quantitatively evaluate the roughness coefficient of road aggregates, the accuracy requirements must first be met. Moreover, the measurement instruments, test methods, and calculation processes should not be too complicated and should be characterized by a fast measurement speed and convenient statistical analysis. Therefore, the contact measurement method was commonly used to quickly calculate the $2 \mathrm{D}$ roughness of the profile contour of the aggregate surface and 
the $3 \mathrm{D}$ topography data can also be obtained via a large amount of $2 \mathrm{D}$ contour data interpolation $[12,13]$. In contrast, the high-precision noncontact measurement technology based on the optical principle has several advantages for obtaining data on the surface topography of rock materials [14]. A 3D scanning device can quickly obtain point cloud data describing the $3 \mathrm{D}$ features of the aggregate particles. These data can be used for the physical reconstruction of the aggregate and the quantification of $3 \mathrm{D}$ morphological parameters [15].

The quantitative evaluation methods for the characterization of aggregate surface roughness primarily include the fractal mathematics method and statistical parameter method [16]. In the fractal mathematics method, more attention is paid to the correlation between the characteristic fractal dimension of the surface topography of the rock structure and the roughness and mechanical properties [17]. In contrast, in the statistical parameter method, quantitative evaluation is conducted by establishing the regression relationship between the characteristic parameters of the surface topography of rock materials and the roughness index [15]. The joint roughness coefficient (JRC) recommended by the International Society of Rock Mechanics was commonly used as the evaluation index of the surface texture roughness of the rock aggregate [18]. In geotechnical engineering research, roughness is often used to analyze the correlations between the rock surface profile and the interface mechanics and seepage characteristics [19]. In road engineering, the roughness coefficient can also be used as an important index to analyze the surface texture roughness of aggregate particles and the correlation between asphalt and aggregate adhesion.

Therefore, in this study, the collection methods for aggregate surface morphology data and the applicability of the joint roughness coefficient (JRC) to the evaluation of the changes of the mesostructure of the aggregate surface texture are investigated. First, the measurement and quantitative evaluation method of the $2 \mathrm{D}$ roughness of the aggregate surface based on contact measurement is studied, and the anisotropic characteristics of aggregate surface texture roughness are analyzed. Second, the measurement and quantitative evaluation method of the $3 \mathrm{D}$ roughness of the aggregate surface based on $3 \mathrm{D}$ scanning technology is studied, and the size effect and resource characteristics of the aggregate surface texture roughness are analyzed. In addition, a polishing test of the aggregate was conducted to explore the influences of the resource characteristics and polishing degree on the surface roughness of aggregates.

\section{Materials and Methods}

2.1. Materials. Four types of coarse aggregates with different lithologies were obtained from the Highway Science and Technology Research Institute of Yunnan Province. The aggregate particle size range was $16-19 \mathrm{~mm}$, and the aggregates were produced using jaw and counterattack crushers. The technical indices of the raw materials were obtained according to the Chinese specification "Test Methods of Aggregate for Highway Engineering” (JTG E42-
2005). The technical indices of the coarse aggregates are listed in Table 1.

2.2. Evaluation Index of Surface Roughness. To quantitatively analyze the roughness of the surfaces of road aggregates, the joint roughness coefficient (JRC) was used as an evaluation index in this study. Combining engineering experience and experimental research results, Barton (1977) presented 10 typical rock surface contour lines with values ranging from 0 to 20 to evaluate the JRC value [20], as shown in Table 2.

\subsection{Aggregate Surface Topography Feature Data Collection}

2.3.1. Collection Method of 2D Contour Line. A Kasaka FGA51 high-precision stylus profiler, which operates on the principle of the needle-tracing method [21], was used to obtain the $2 \mathrm{D}$ profile curves of the aggregate surface (see Figure 1(a)). The $x$-axis measurement accuracy of the profiler is $1.2 \mu \mathrm{m}$, the grating resolution is $0.1 \mu \mathrm{m}$, the $Z_{1}$ measurement accuracy is $1.0 \mu \mathrm{m}$, the resolution is $0.05 \mu \mathrm{m}$, and the measurement speed range is $0.02-4 \mathrm{~mm} / \mathrm{s}$; these characteristics meet the requirements of aggregate surface topography measurement (see Figure 1(b)). During the measurement process, the aggregate was fixed on a precision linear motion guideway in the $x$-direction so that the stylus was in contact with the surface of the specimen. Then, the stylus movement speed was set to $0.5 \mathrm{~mm} / \mathrm{s}$, the fluctuation range was set to $\pm 0.02 \mathrm{~mm} / \mathrm{s}$, the sampling step was set to $2 \mu \mathrm{m}$, and the sampling line distance was set to $10 \mathrm{~mm}$. By setting the parameters of the measurement system, the measurement command was issued, and the computer accepted the command to drive the control instruction to make the stylus move to the moving guideway. When the aggregate moved at the sampling interval along the $x$-axis, the $x$-coordinate of the measurement point was obtained at the position to be measured, and the stylus moved up and down with the fluctuation of the surface profile, causing the $z_{1}$-axis digital sensor to output electrical signals. The signals were transmitted to the computer for processing via the photoelectric conversion processing circuit, and the $z$-coordinate could then be determined. This process was repeated for the observation section of the aggregate surface presented in Figure 1(c) to obtain the corresponding 2D profile curve. Finally, the data from the effective test length of $10 \mathrm{~mm}$ were filtered and digitized and were drawn in proportion to the coordinate grid. The roughness coefficients $J R C^{2 \mathrm{D}}$ of 9 contours of the aggregate surface were estimated from the visual comparison with the 10 typical rock surface contour lines shown in Table 2, as presented in Figure 1(d).

2.3.2. Collection Method of 3D Contour Surface. An EinScan-S 3D scanner was used to obtain the point cloud data that contain information about the surface geometric characteristics of the aggregate particles. The resolution of the profiler lens is $3264 \times 2488$, the scanning size is $200 \times 200 \mathrm{~mm}$, the measurement accuracy is $20 \mu \mathrm{m}$, there are 8 million effective $3 \mathrm{D}$ points, and omnidirectional scanning 
TABLE 1: Technical indices of the coarse aggregates.

\begin{tabular}{lccccc}
\hline Lithology & Crushing value (\%) & Wear value (\%) & Polishing value & Water absorption rate (\%) & Apparent relative density $\left(\mathrm{g} / \mathrm{cm}^{3}\right)$ \\
\hline Granite & 18.1 & 21.5 & 46 & 0.37 & 2.654 \\
Diabase & 12.6 & 10.0 & 65 & 0.77 & 2.765 \\
Basalt & 10.5 & 8.9 & 58 & 0.63 & 2.724 \\
Limestone & 21.5 & 19.4 & 42 & 0.72 & 2.698
\end{tabular}

TABLE 2: Barton standard roughness contours.

\begin{tabular}{l} 
Value range of $J R C$ \\
\hline $0 \sim 2$ \\
$2 \sim 4$ \\
$4 \sim 6$ \\
$6 \sim 8$ \\
$8 \sim 10$ \\
$10 \sim 12$ \\
$12 \sim 14$ \\
$14 \sim 16$ \\
$16 \sim 18$ \\
$18 \sim 20$
\end{tabular}

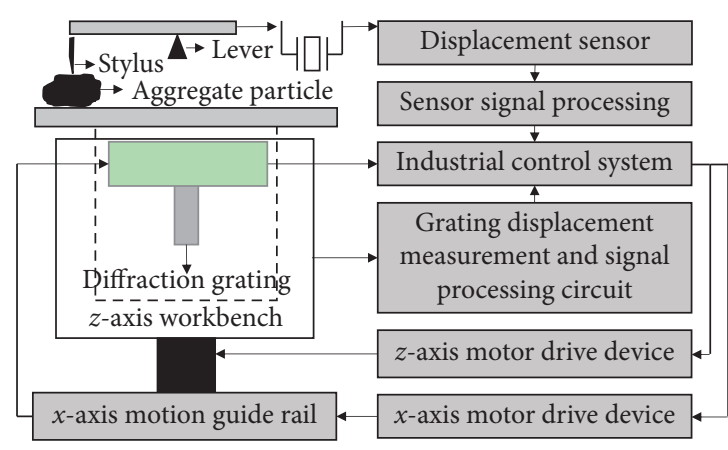

(a)

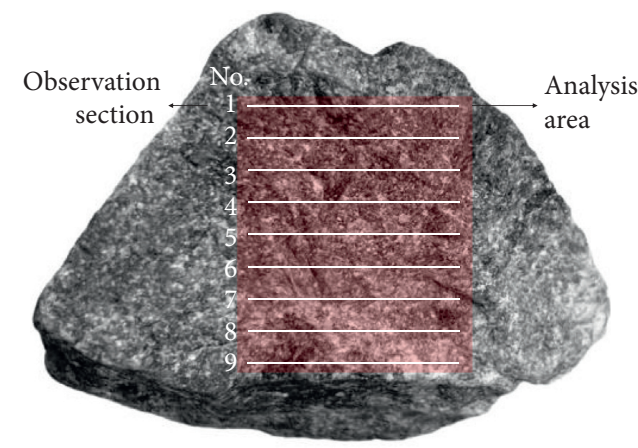

(c)

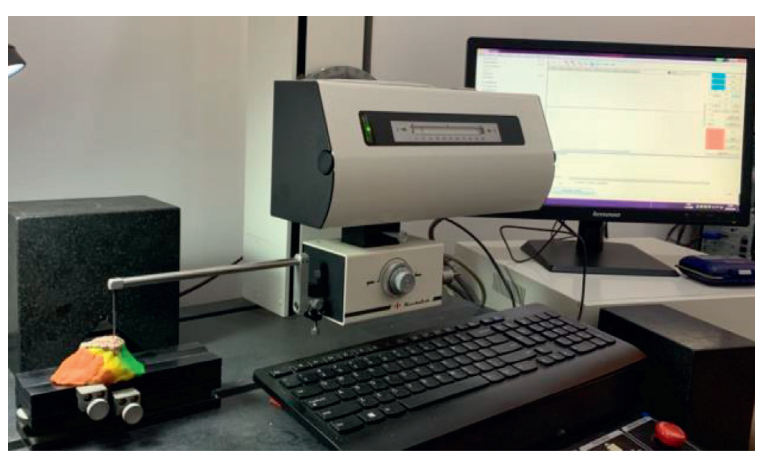

(b)

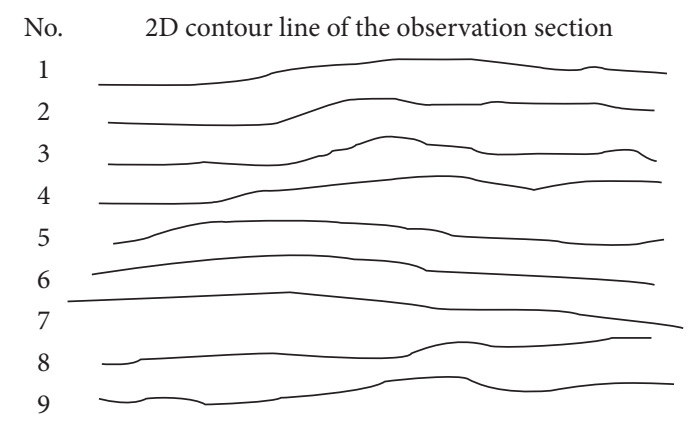

(d)

Figure 1: Collection method of 2D profile curves of the aggregate. (a) Principle of the needle-tracing method. (b) High-precision stylus profiler. (c) Observation section of the aggregate surface. (d) $2 \mathrm{D}$ profile curve of the observation section.

is supported; these characteristics meet the requirements of aggregate surface topography measurement (see Figure 2(a)).

The 3D scanner system operates on the principle of whitelight interferometry [22, 23]. During the measurement process, the aggregate sample was placed on the stage, the white-light emitted by the light source was refracted by the lens and the beam splitter and was irradiated to the rough textured surface of the aggregate. Then, the white-light intensity of the light source was adjusted according to the light 


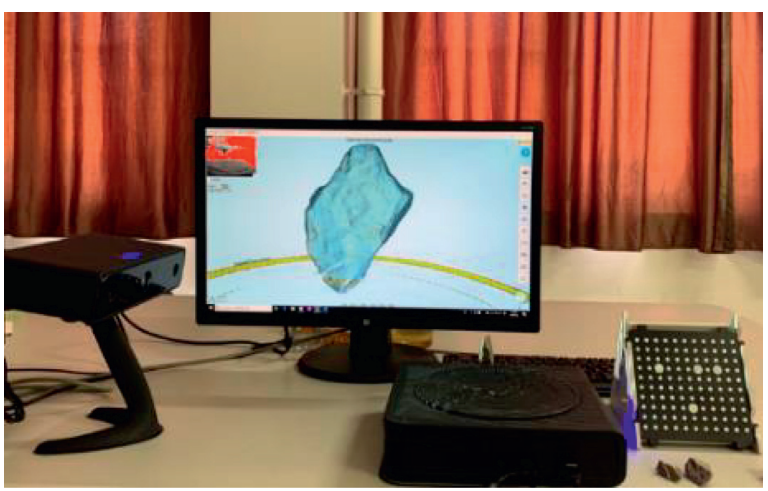

(a)

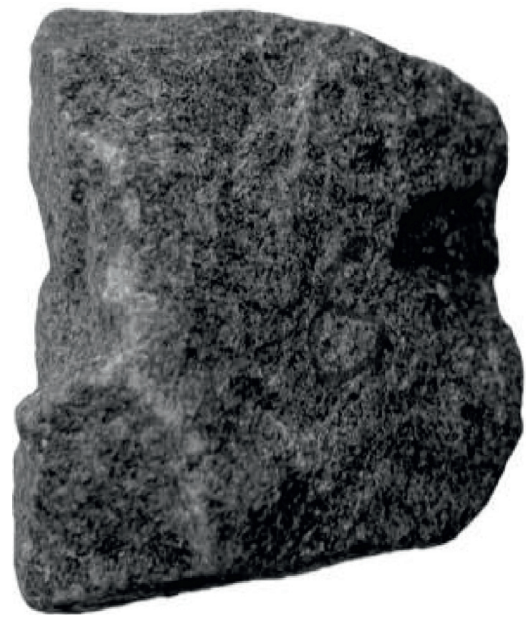

(c)

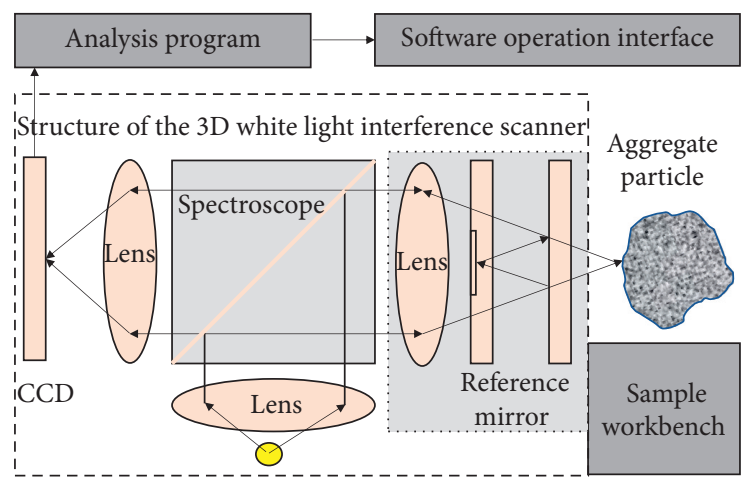

(b)

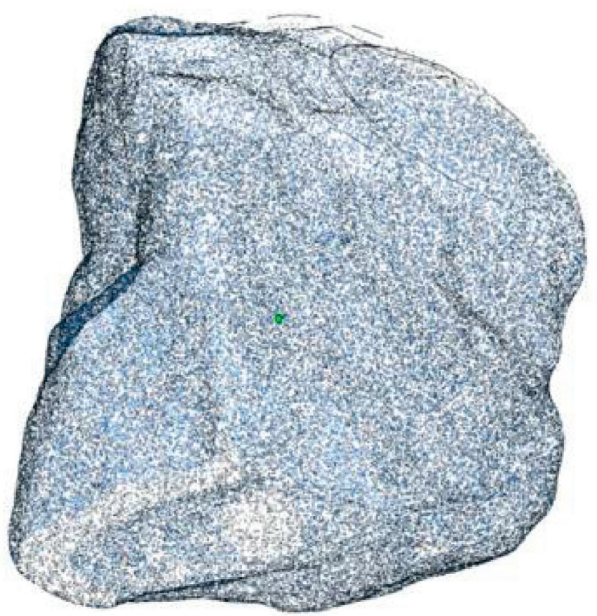

(d)

FIgure 2: Point cloud data acquisition instrument and 3D scanning principle. (a) EinScan-S 3D scanner. (b) Principle of 3D scanning technology. (c) Coarse aggregate particle. (d) 3D coordinate lattice model.

intensity and color temperature of the room, and the carrier table was simultaneously adjusted for calibration until the interference image of the aggregate surface captured by the charge-coupled device (CCD) camera in the visual interface of the software met the analysis accuracy requirements. After setting the scanning range, sampling step length, and number of frames, multiframe images of interference fringes on the $3 \mathrm{D}$ contour surface of the aggregate were obtained via the $\mathrm{CCD}$, and the $3 \mathrm{D}$ scanning point of the aggregate surface in the coordinate system of the scanner was calculated by the analysis software. The principle of $3 \mathrm{D}$ scanning technology is presented in Figure 2(b).

After scanning the $3 \mathrm{D}$ contour surface of the aggregate test sample from multiple angles (see Figure 2(c)), the iterative closest point (ICP) algorithm in the Imageware software was used to register the point cloud of multiple scans. The purpose of the ICP algorithm was to determine the rotation and shift parameters of the point cloud scans from different angles to register the dataset and obtain an optimal match for the data with different incident angles due to changes in the light source [24].

The registered dataset was imported into the PCL library to eliminate outliers and noise. This library is a large crossplatform open-source $\mathrm{C}++$ programming library containing many algorithms and data structures related to point clouds, including point cloud acquisition, filtering, segmentation, registration, retrieval, feature extraction, recognition, tracking, surface reconstruction, and visualization [25]. The VoxelGrid filter was used for noise reduction. A 3D mesh of the aggregate particle was generated after eliminating $96 \%$ of the point cloud data (see Figure 2(d)).

\subsection{Quantitative Characterization of the Surface Roughness}

\subsubsection{Calculation Method of 2D Contour Line Roughness}

(1) Characteristic Parameter Method. To quantitatively analyze the roughness of the two-dimensional profiles of the rock materials, a least-squares midline running through the sampling length was used as the baseline [26, 27], as shown in Figure 3.

The regression equation of the relationship between the geometric characteristic parameters and roughness proposed by Tse and Crude is generally used to calculate the $2 \mathrm{D}$ roughness $\left(\mathrm{JRC}^{2 \mathrm{D}}\right)$ of the surface profile of rock materials [28] and is defined as follows:

$$
\mathrm{JCR}^{2 D}=32.2+32.47 \lg Z_{2} .
$$




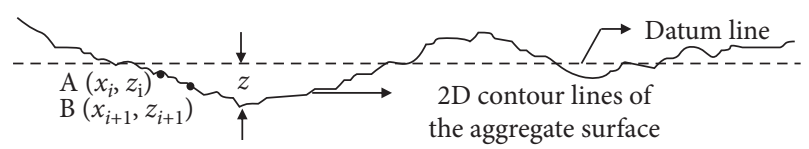

Figure 3: Characteristic parameter of the 2D profile curve.

The parameter $Z_{2}$ is a characteristic parameter of the slope of the rock surface that is not affected by the position of the calculated reference line [29] and is expressed as follows:

$$
z_{2}=\frac{1}{L} \sqrt{\int_{x=0}^{x=L}\left(\frac{\mathrm{d} y}{\mathrm{~d} x}\right)^{2} \mathrm{~d} x}
$$

When using 3D point cloud data to calculate the roughness of the $2 \mathrm{D}$ contour of an aggregate surface, equation (2) can be approximately expressed as follows:

$$
\begin{aligned}
z_{2} & =\frac{1}{L} \sqrt{\sum_{i=1}^{n-1} \frac{\left(z_{i+1}-z_{i}\right)^{2}}{x_{i+1}-x_{i}}}, \\
L & =\sum_{i=1}^{n-1}\left(x_{i+1}-x_{i}\right),
\end{aligned}
$$

where $L$ is the total length of the $2 \mathrm{D}$ profile contour line, $n$ is the number of calculated samples, and $x_{\mathrm{i}}$ and $z_{\mathrm{i}}$ are the point cloud coordinates on the contour line.

(2) Trace Length Characterization Method. To quantitatively evaluate the roughness coefficient of road aggregates in practical engineering applications, the accuracy requirements must first be met. Moreover, the measurement instruments, test methods, and calculation processes should not be too complicated and should be characterized by a fast measurement speed and convenient statistical analysis. Therefore, the trace length characterization method proposed by Soudan was used to quickly calculate the $2 \mathrm{D}$ roughness of the profile contour of the aggregate surface [30] and is defined as follows:

$$
R_{p}=\frac{\sum_{i=1}^{n-1}\left[\left(x_{i+1}-x_{i}\right)^{2}+\left(y_{i+1}-y_{i}\right)^{2}\right]^{(1 / 2)}}{L},
$$

where $R_{p}$ is the ratio of the actual length of the profile line to its straight-line length and $x_{\mathrm{i}}, x_{\mathrm{i}+1}, y_{\mathrm{i}}$, and $y_{\mathrm{i}+1}$ are the relative coordinates of point $i$ and point $i+1$, as indicated by the subscripts.

Table 3 presents the functional relationship between $R_{\mathrm{p}}$ and $\mathrm{JRC}^{2 \mathrm{D}}$ under different sampling intervals [29].

(3) Evaluation Accuracy of 2D Contour Line Roughness. According to the relative coordinate data of the measured curve exhibited in Figure 1(d), the roughness coefficients $\mathrm{JRC}^{2 \mathrm{D}}$ of 9 contours of the aggregate surface were first calculated based on the characteristic parameter method. The measurement point data of each contour curve were then sampled at $0.5 \mathrm{~mm}$ intervals and substituted into
TABLE 3: The relationship between $R_{p}$ and JRC.

\begin{tabular}{lcc}
\hline $\begin{array}{l}\text { Sample } \\
\text { interval }(\mathrm{mm})\end{array}$ & Functional relation & $\begin{array}{c}\text { Correlation } \\
\text { coefficient }\end{array}$ \\
\hline 0.25 & $\mathrm{JCR}=558.68 \sqrt{R_{p}}-557.13$ & 0.951 \\
0.50 & $\mathrm{JCR}=559.73 \sqrt{R_{p}}-597.46$ & 0.945 \\
1.00 & $\mathrm{JCR}=702.67 \sqrt{R_{p}}-699.99$ & 0.951 \\
\hline
\end{tabular}

equation (5) to determine the elongation rate $R_{p}$ of the contour line. The roughness coefficient $\mathrm{JRC}^{2 \mathrm{D}}$ of each $2 \mathrm{D}$ profile contour line was calculated by the functional relationship between $R_{p}$ and $\mathrm{JRC}^{2 \mathrm{D}}$ at a sampling interval of $0.50 \mathrm{~mm}$. The calculation results of the two analysis methods are reported in Table 4 .

From the calculation results, it can be seen that the characteristic parameter method and the trace length method can both quantitatively characterize the roughness coefficient of the $2 \mathrm{D}$ profile of the aggregate texture, and the calculation deviation was within $13 \%$. Similarly, other test samples were also governed by the same law, and a good correlation was found. The comparative evaluation results demonstrate that the calculation deviation of the two roughness characterization methods was mainly caused by the difference in the sampling interval. Compared with that of the characteristic parameter method $(0.002 \mathrm{~mm})$, the sampling interval of the trace length method was $0.5 \mathrm{~mm}$. Under the relatively large sampling interval, a portion of the mesomorphological changes of the measurement curve could not be collected, resulting in the overall low roughness value.

2.4.2. Calculation Method of 3D Contour Surface Roughness. The $2 \mathrm{D}$ roughness coefficient of the aggregate cannot fully reflect the geometric shape of the aggregate surface, so it is necessary to use the $3 \mathrm{D}$ roughness coefficient to characterize the geometric characteristics of the rough texture of the aggregate profile. In the calculation of $3 \mathrm{D}$ roughness, the weighted average method and characteristic parameter method are typically used.

(1) Weighted Average Method. The roughness JRC ${ }^{2 D}$ of a large number of $2 \mathrm{D}$ contours on the surface of a rock material can be measured, and the $3 \mathrm{D}$ average roughness $\overline{\mathrm{JRC}}$ of this area can be calculated by the weighted average method, as follows:

$$
\overline{\mathrm{JCR}}=\frac{1}{m} \sum_{i=1}^{m} \mathrm{JRC}_{i}^{2 D},
$$

where $\overline{\mathrm{JRC}}$ is the $3 \mathrm{D}$ average roughness, $\mathrm{JRC}_{\mathrm{i}}{ }^{2 \mathrm{D}}$ is the roughness of each $2 \mathrm{D}$ undulating curve, and $m$ is the number of section lines.

(2) Characteristic Parameter Method. It is assumed that the coordinates of the point cloud on the rough surface of a rock are continuously differentiable. The root mean square $Z_{2 \mathrm{~s}}$ of the $3 \mathrm{D}$ characteristic 
TABLE 4: Roughness evaluation of form line based on trace length method.

\begin{tabular}{|c|c|c|c|c|c|c|c|c|c|c|}
\hline Number of $2 \mathrm{D}$ contour lines & & 1 & 2 & 3 & 4 & 5 & 6 & 7 & 8 & 9 \\
\hline Characteristic parameter method & $\mathrm{JRC}^{2 \mathrm{D}}$ & 13.1 & 14.0 & 19.4 & 12.3 & 14.2 & 11.1 & 10.8 & 18.7 & 17.8 \\
\hline & $R_{\mathrm{p}}$ & 1.186 & 1.188 & 1.207 & 1.183 & 1.189 & 1.179 & 1.177 & 1.206 & 1.203 \\
\hline ength & $\mathrm{JRC}^{2 \mathrm{D}}$ & 12.0 & 12.7 & 17.5 & 11.4 & 12.9 & 10.5 & 9.7 & 17.3 & 16.6 \\
\hline
\end{tabular}

parameter of the relative height fluctuation can be calculated as follows [31]:

$$
Z_{2 s}=\left\{\frac{1}{L_{x} L_{y}} \int_{0}^{L_{x}} \int_{0}^{L_{y}}\left[\left(\frac{\partial z(x, y)}{\partial x}\right)^{2}+\left(\frac{\partial z(x, y)}{\partial y}\right)^{2}\right] \mathrm{d} x \mathrm{~d} y\right\}^{(1 / 2)}
$$

When using the $3 \mathrm{D}$ point cloud data to calculate the $3 \mathrm{D}$ profile roughness coefficient $J R C^{3 \mathrm{D}}$ of an aggregate surface, the approximate formula is as follows:

$Z_{2 s}=\left\{\frac{1}{\left(N_{x}-1\right)\left(N_{y}-1\right)}\left[\frac{1}{\Delta x^{2}} \sum_{j=1}^{N_{x}-1} \sum_{i=1}^{N_{y}-1} \frac{\left(z_{i+1, j+1}-z_{i, j+1}\right)^{2}+\left(z_{i+1, j}-z_{i, j}\right)^{2}}{2}+\frac{1}{\Delta y^{2}} \sum_{j=1}^{N_{y}-1} \sum_{i=1}^{N_{x}-1} \frac{\left(z_{i+1, j+1}-z_{i+1, j}\right)^{2}+\left(z_{i, j+1}-z_{i, j}\right)^{2}}{2}\right]\right\}^{(1 / 2)}$,

where $N_{x}$ is the number of point clouds on the $x$-axis in the length direction of the rock profile, $N_{x}$ is the number of point clouds on the $y$-axis in the height direction, $\Delta x$ is the sampling spacing of point clouds on the $x$-axis, $\Delta y$ is the sampling spacing of point clouds on the $y$-axis, and $Z_{i}$ and $Z_{i+1}$ are the coordinates of the $i$-th point and the $(i+1)$-th point in the $z$-axis direction of the roughness height, respectively. The relevant parameters are presented in Figure 4.

(3) Evaluation Accuracy of 3D Contour Surface Roughness. According to the roughness coefficient $\mathrm{JRC}^{2 \mathrm{D}}$ of 9 contours of the aggregate surface, the 3D average roughness $\overline{\mathrm{JRC}}$ of the analysis area of the aggregate surface was calculated to be 14.6 via equation (6). The texture feature of the analysis area was then evaluated by the $3 \mathrm{D}$ contour surface roughness $\mathrm{JRC}^{3 \mathrm{D}}$. After scanning the $3 \mathrm{D}$ contour surface of the aggregate test sample from multiple angles, the data point cloud of the analysis area (Figure 1(c)) of the aggregate fracture surface was sampled at intervals of $10 \times 10 \mathrm{~mm}$, that is, $\Delta x=\Delta y=0.25 \mathrm{~mm}$. Equation (8) was used to calculate the characteristic parameter $Z_{2 s}$, and the $3 \mathrm{D}$ contour surface roughness $\mathrm{JRC}^{3 \mathrm{D}}$ of the analysis area of the aggregate surface was then calculated to be 13.8 via equation (1). The differences and correlations between the two calculation methods for the calculation of the $3 \mathrm{D}$ roughness are discussed in the subsequent section.

2.5. Change Method for the Surface Roughness of the Aggregate. An aggregate polishing test was designed to test the accuracy of the roughness coefficient $J R C$ for the analysis of changes of the aggregate surface roughness. In the test, 1200\# carborundum with a 95\% alumina content was used as an abrasive, and a vibrating polishing machine was employed to change the mesostructures of the surface textures of the four aggregates with different lithologies. The steps of the aggregate polishing test were as follows:

(1) After fully soaking the abrasive in water, it was drained with a basket and poured into the vibrating polishing machine.

(2) The power was turned on and the wet water-drained aggregate was arranged in the abrasive in the vibrating polishing machine to be polished from different directions one-by-one.

(3) After the carborundum was uniformly added to the mixture, the polishing time was set according to the polishing requirements; after the polishing test was completed, the carborundum in the mixture was washed with clean water.

At the end of each polishing test, the profile point cloud data of the particle surface were collected again, and the changes of the aggregate surface roughness under different polishing conditions were compared and analyzed.

\section{Results and Discussion}

3.1. Anisotropy Analysis of Aggregate Surface Roughness. To analyze the differences in the roughness of the $2 \mathrm{D}$ contour line of the aggregate surface in different directions and angles, coarse aggregates with a particle size between 16 and $19 \mathrm{~mm}$ were used as the research object, and the size of the aggregate fracture surface was $10 \times 10 \mathrm{~mm}$. The range was used as the analysis area, as shown in Figure 5(a). Twelve observation cross sections were, respectively, set up along the $x$ - and $y$-axes at equal intervals of $0.8 \mathrm{~mm}$, as shown in Figures 5(b) and 5(c). The origin of the coordinates and the direction of $0^{\circ}$ in 


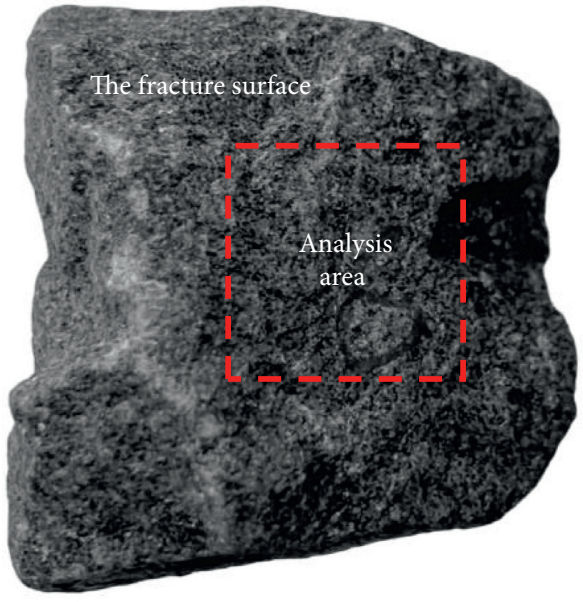

(a)

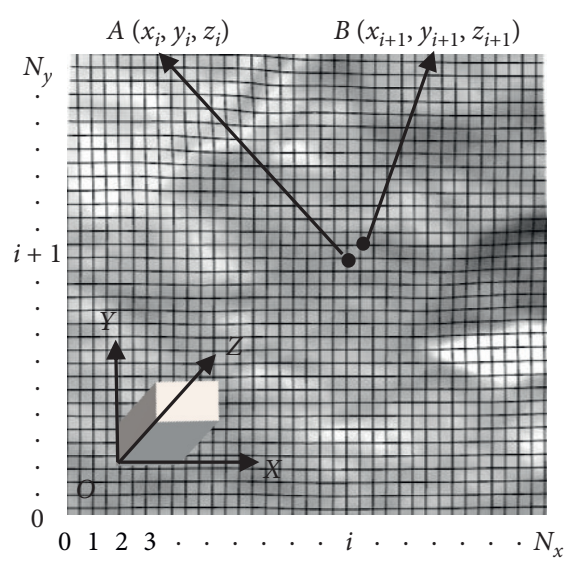

(b)

Figure 4: 3D contour surface of the aggregate. (a) Analysis area. (b) Contour surface point cloud.

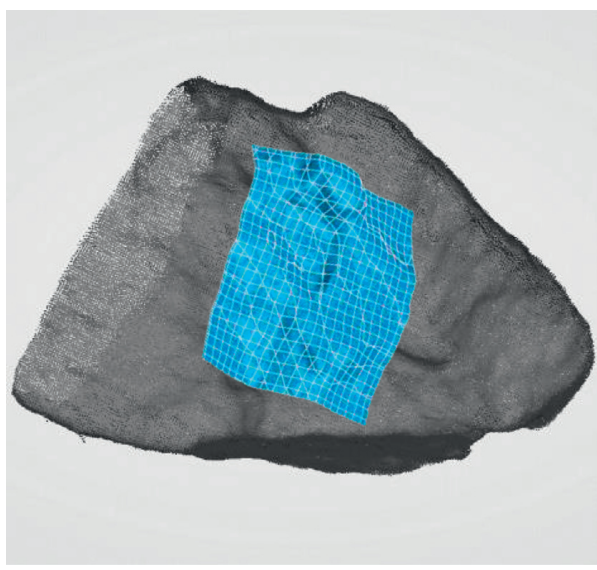

(a)

No. $11 \quad 2 \quad 3 \quad \begin{array}{lllllllllllll} & 2 & 4 & 5 & 6 & 7 & 8 & 9 & 10 & 11 & 12\end{array}$

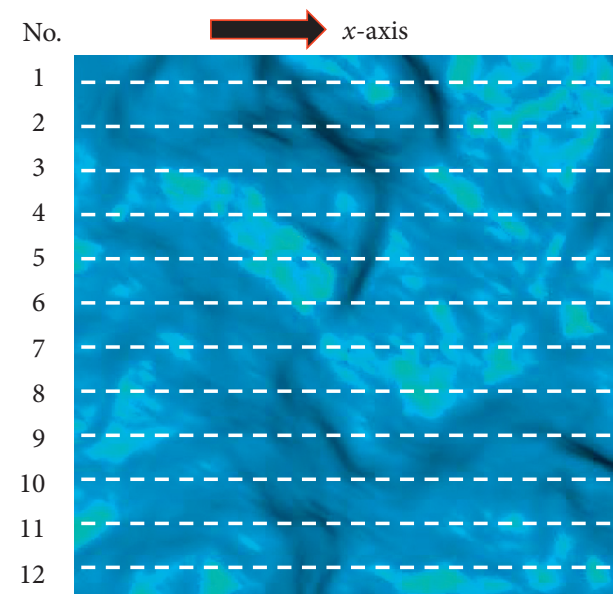

(b)

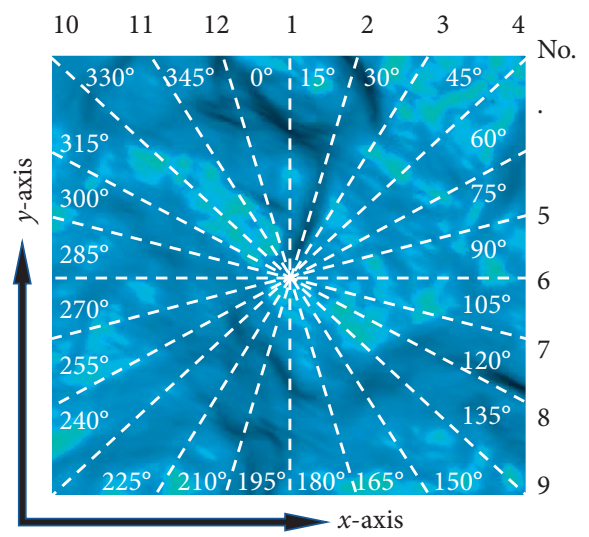

(d)

Figure 5: Observation sections of the aggregate surface. (a) Analysis area of the aggregate fracture surface. (b) 2D profile position distribution along the $x$-axis. (c) 2D profile position distribution along the y-axis. (d) $2 \mathrm{D}$ profile position distribution along the circumference. 
the analysis area was defined with the direction of $0^{\circ}$ as the reference line, and an observation section was set up every $15^{\circ}$ through this point for a total of 12 observation sections, as shown in Figure 5(d).

The characteristic point coordinate data of the observation section contour lines were measured from the contact stylus profiler, and the $2 \mathrm{D}$ contour curve was drawn. According to the functional relationship in the characteristic parameter method, the $\mathrm{JRC}^{2 \mathrm{D}}$ value of each curve was programmed in MATLAB, as reported in Tables 5-7.

The test results demonstrate that, under different observation section sampling rules, the roughness of the $2 \mathrm{D}$ contour lines of the aggregate particle surface was different, and the apparent morphologies were quite different and had no correlation with the sampling direction or angle, thereby exhibiting anisotropy. When the $\mathrm{JRC}^{2 \mathrm{D}}$ index is used to characterize the roughness characteristics of the texture of aggregates, the randomness of the selection of the observation cross sections will lead to deviations in the evaluation of roughness. Therefore, the $2 \mathrm{D}$ roughness index cannot describe the overall morphology of the aggregate surface, and it is necessary to use the $3 \mathrm{D}$ roughness index to comprehensively characterize the spatial geometric characteristics of the aggregate particle profile.

\subsection{Influence of the Size Effect on Aggregate Surface Roughness.} To analyze the roughness of the different observation areas with the same centroid and different dimensions of the aggregate fracture surface, the weighted average method and the characteristic parameter method were used to calculate the $3 \mathrm{D}$ average roughness of the analysis area of the aggregate fracture surface.

Via the weighted average method, equation (5) was used to calculate the $3 \mathrm{D}$ average roughness of the analysis area of the aggregate fracture surface. The calculation results of the sampling methods for the three observation sections along the $x$-axis, $y$-axis, and circumference were $13.2,10.6$, and 12.2 , respectively.

Using the characteristic parameter method, the data point cloud of the analysis area of the aggregate surface was sampled at intervals of $0.1 \mathrm{~mm}$, that is, $\Delta x=\Delta y=0.1 \mathrm{~mm}$. In MATLAB, equation (7) was used to calculate the characteristic parameter $Z_{2 s}$, and the $3 \mathrm{D}$ contour surface roughness $\mathrm{JRC}^{3 \mathrm{D}}$ of the analysis area of the aggregate surface was then calculated to be 12.6 by equation (1). This calculation result is closer to the average roughness coefficient of the $12 \mathrm{ob}-$ servation sections taken along the circumference calculated by the weighted average method.

The weighted average method (12 observed sections along the circumference) and the characteristic parameter method were used to study the influence of the area difference of the aggregate surface analysis on the roughness calculation results. The $3 \mathrm{D}$ roughness of the four analysis areas with the same centroid and different dimensions of the aggregate fracture surface was, respectively, calculated, as presented in Figure 6.

The calculation results reveal that the rough texture of the aggregate surface was characterized not only by
TABLE 5: 2D roughness of contour lines along the $x$-axis.

\begin{tabular}{llr}
\hline Number & 2D contour line of aggregate fracture surface & $\mathrm{JRC}^{2 \mathrm{D}}$ \\
\hline 1 & & 8.4 \\
2 & & \\
3 & & \\
4 & & \\
5 & & 12.3 \\
6 & & 13.4 \\
7 & & 14.3 \\
8 & & 15.7 \\
9 & & 14.3 \\
10 & \\
11 & & 16.1 \\
12 & & 12.6 \\
\end{tabular}

TABLE 6: 2D roughness of contour lines along the $y$-axis.

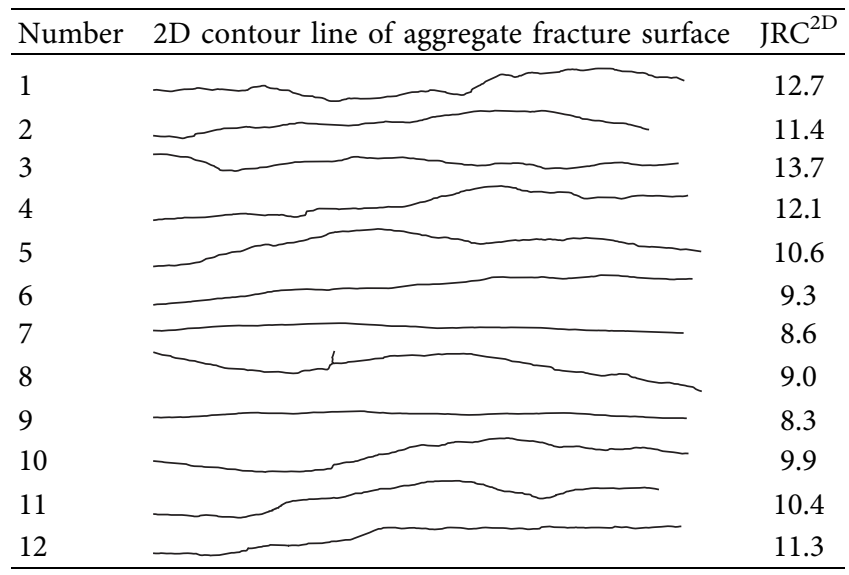

TABLE 7: 2D roughness of contour lines along the circumference.

\begin{tabular}{|c|c|c|}
\hline Number & 2D contour line of aggregate fracture surface & $\mathrm{JRC}^{2 \mathrm{D}}$ \\
\hline 1 & & 14.1 \\
\hline 2 & & 12.8 \\
\hline 3 & & 12.3 \\
\hline 4 & & 10.6 \\
\hline 5 & & 9.4 \\
\hline 6 & & 10.8 \\
\hline 7 & & 11.6 \\
\hline 8 & & 12.3 \\
\hline 9 & & 13.2 \\
\hline 10 & & 13.0 \\
\hline 11 & & 13.5 \\
\hline 12 & 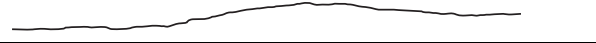 & 12.9 \\
\hline
\end{tabular}

anisotropy at the $2 \mathrm{D}$ level but also by the size effect at the $3 \mathrm{D}$ level. With the increase of the observation range of the aggregate surface, the $2 \mathrm{D}$ profile roughness of each observed section and the $3 \mathrm{D}$ profile roughness of the analysis area exhibited decreasing trends. The anisotropic characteristics 

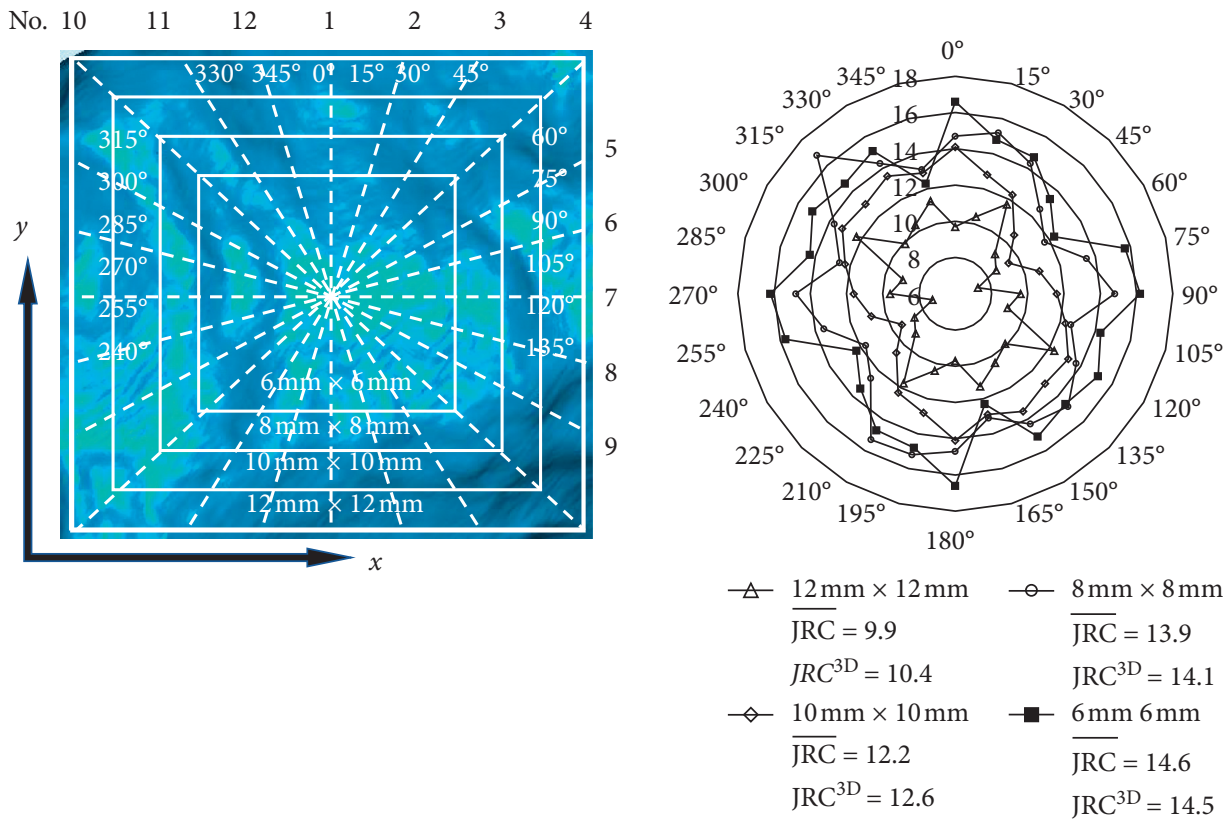

FIGURE 6: The size effect of the roughness of the aggregate surface.

displayed certain similarities in different observation ranges, but no correlation was found. Similarly, other test samples were also governed by the same law. Therefore, when evaluating the $3 \mathrm{D}$ roughness of an aggregate surface, the analysis area of the aggregate surface should be maintained at a constant value during the test to ensure the comparability of the evaluation results.

3.3. Influence of Lithology Characteristics on the Aggregate Surface Roughness. The point cloud data of aggregates with four different lithologies were obtained by $3 \mathrm{D}$ white-light interferometry, and the weighted average method (observation data were collected every $15^{\circ}$ along the circumference) and the characteristic parameter method were used to evaluate the fracture surface of each aggregate within the range of $10 \times 10 \mathrm{~mm}$. The roughness results are presented in Table 8.

The test results demonstrate that when the weighted average method and the characteristic parameter method are used to evaluate the $3 \mathrm{D}$ roughness in the same analysis area, the difference between the calculation results can be controlled below $10 \%$, and the results, therefore, exhibit a good correlation. Under the experimental conditions of this study, the average $3 \mathrm{D}$ roughness value of the limestone aggregate sample was the highest, that of granite was the lowest, and those of basalt and diabase were in the middle. When the weighted average method was used to evaluate the $3 \mathrm{D}$ roughness of the aggregate surface, the $\overline{\mathrm{JCR}}$ values of the granite samples were found to range from 8 to 16 , and the roughness among the samples varied greatly. In contrast, when the characteristic parameter method was used, the $J R C^{3 D}$ values of the granite samples ranged from 9 to 14 , the variation of roughness among the samples was relatively small, and the other test samples were also governed by the same law. The comparative evaluation results demonstrate that the calculation deviation of the two roughness characterization methods was mainly caused by the differences in the test methods and data accuracy. During the process of contact measurement, factors such as the excessive hardness of the contact probe, unstable moving speeds, and easy lateral sliding will affect the measurement accuracy. In contrast, 3D noncontact measurement technology based on the optical principle is used to obtain the contour surface feature information of an object and has obvious advantages in the collection of the surface topography data of rock-like materials.

3.4. Influence of Polishing on the Aggregate Surface Roughness. To test the accuracy of the $3 \mathrm{D}$ roughness coefficient JRC ${ }^{3 \mathrm{D}}$ for the analysis of changes of the aggregate surface roughness, an aggregate polishing test was designed. Carborundum with a $95 \%$ alumina content was used as an abrasive, and a vibrating polishing machine was employed to change the mesostructures of the surface textures of the four aggregates with different lithologies. At the end of each polishing test, the $3 \mathrm{D}$ profile point cloud data of the particle surface were collected again, and the changes of the aggregate surface roughness under different polishing conditions were compared and analyzed. The results are reported in Table 9. The changing trend of the roughness of each lithologic aggregate test sample under different polishing times is shown in Figure 7.

It is evident from the test data that the average roughness of the fracture surface of the limestone aggregate sample was the highest, that of granite was the smallest, and that of basalt and diabase were in the middle. With the increase in polishing time, the rough texture surface of aggregate gradually wore away, which shows that the roughness of the coarse 
TABLE 8: The basic properties of aggregates.

\begin{tabular}{|c|c|c|c|c|c|c|c|}
\hline \multirow[t]{2}{*}{ Lithology } & \multirow[t]{2}{*}{ Number of aggregate samples } & \multicolumn{3}{|c|}{$3 \mathrm{D}$ average roughness $(\overline{\mathrm{JCR}})$} & \multicolumn{3}{|c|}{$\begin{array}{c}\text { 3D topographic roughness } \\
\left(\mathrm{JRC}^{3 \mathrm{D}}\right)\end{array}$} \\
\hline & & Max & Min & Average & Max & Min & Average \\
\hline Granite & 50 & 15.7 & 8.3 & 11.9 & 13.6 & 9.7 & 11.5 \\
\hline Diabase & 50 & 16.4 & 11.7 & 13.8 & 17.4 & 12.2 & 14.6 \\
\hline Basalt & 50 & 16.4 & 10.2 & 13.7 & 15.7 & 11.0 & 13.1 \\
\hline Limestone & 50 & 18.2 & 12.0 & 15.1 & 18.3 & 11.1 & 15.8 \\
\hline
\end{tabular}

TABLE 9: The variation of the $\mathrm{JRC}^{3 \mathrm{D}}$ values of aggregates with different lithologies with the polishing time.

\begin{tabular}{lccccccccccccc}
\hline \multirow{2}{*}{$\begin{array}{c}\text { Polishing time (h) } \\
\text { Number of aggregate }\end{array}$} & \multicolumn{3}{c}{ Granite } & \multicolumn{3}{c}{ Diabase } & \multicolumn{3}{c}{ Basalt } & \multicolumn{2}{c}{ Limestone } \\
& samples & Max & Min & Average & Max & Min & Average & Max & Min & Average & Max & Min & Average \\
\hline 0.0 & 20 & 13.6 & 9.7 & 11.5 & 17.4 & 12.2 & 14.6 & 15.7 & 11.0 & 13.1 & 18.3 & 11.1 & 15.8 \\
0.5 & 20 & 13.1 & 9.5 & 11.0 & 16.5 & 11.7 & 13.7 & 15.1 & 10.5 & 12.4 & 16.01 & 9.63 & 14.1 \\
1.0 & 20 & 12.9 & 9.2 & 10.7 & 15.5 & 11.4 & 13.2 & 14.4 & 10.2 & 12.1 & 14.85 & 8.77 & 12.4 \\
1.5 & 20 & 12.8 & 9.1 & 10.5 & 14.7 & 11.0 & 13.0 & 13.9 & 10.0 & 11.8 & 14.09 & 8.08 & 11.1 \\
2.0 & 20 & 12.5 & 9.2 & 10.4 & 14.6 & 10.7 & 12.8 & 13.3 & 10.0 & 11.4 & 13.50 & 7.11 & 9.8 \\
\hline
\end{tabular}

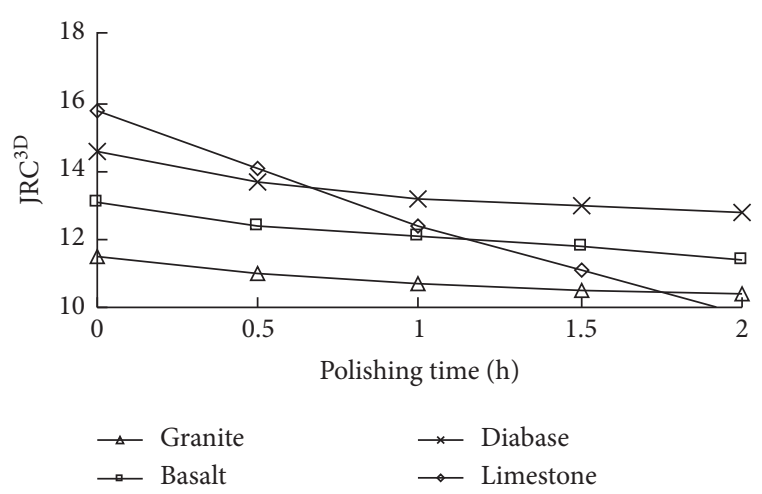

FIGURE 7: Variation trend of aggregate roughness.

aggregate surface of different lithologies decreases with the increase in polishing time. Among them, the average roughness of the fracture surface of limestone decreases the most, followed by basalt and diabase, while the roughness of granite decreases the least. The results show that the wear resistance of the surface texture of granite aggregate was obviously better than that of limestone aggregate, and the wear resistance of diabase aggregate was similar to that of basalt, which was consistent with the attenuation law of the mechanical index of road aggregate in practical engineering.

Under the experimental conditions of this study, when the $3 \mathrm{D}$ roughness of aggregate profile $\mathrm{JRC}^{3 \mathrm{D}} \geq 11.0$, there were many pores and cracks on the aggregate surface, and the texture was uneven, which was beneficial to the formation of good physical adsorption between asphalt and aggregate on the contact surface. The test results demonstrate that the $3 \mathrm{D}$ profile roughness coefficient $\mathrm{JRC}^{3 \mathrm{D}}$ has good sensitivity in the evaluation of the mesostructure changes of the aggregate surface texture and that this coefficient can be used as an evaluation index of the $3 \mathrm{D}$ roughness of road aggregate surfaces.

\section{Conclusions}

Based on the stylus contact measurement method and optical noncontact measurement method, the $2 \mathrm{D}$ and $3 \mathrm{D}$ quantitative evaluation methods of aggregate surface roughness were studied using the roughness coefficient JRC as the evaluation index. The following conclusions can be drawn.

(1) By using contact measurement technology based on the principle of the needle-tracing method, the $2 \mathrm{D}$ profile curves of the aggregate surface can be obtained and can be used to quantitatively characterize the roughness coefficient of the $2 \mathrm{D}$ profile of the aggregate texture obtained by the characteristic parameter method. By using noncontact 3D scanning technology based on the principle of white-light interferometry, the $3 \mathrm{D}$ coordinate data of the analysis area of the aggregate surface can be obtained by the point cloud, which can be used to calculate the $3 \mathrm{D}$ roughness indexes of the aggregate surface after data processing.

(2) When using the JRC ${ }^{2 \mathrm{D}}$ index to evaluate the contour roughness of an aggregate surface, it is necessary to consider that the randomness of the selection of observation sections will lead to the anisotropy of the $2 \mathrm{D}$ roughness evaluation results. The evaluation index of $2 \mathrm{D}$ roughness cannot reflect the overall roughness of an aggregate surface.

(3) Under the experimental conditions of this study, the average $3 \mathrm{D}$ roughness value of the limestone aggregate sample was the highest, that of granite was the lowest, and those of basalt and diabase were in the middle. When the weighted average method was used to evaluate the $3 \mathrm{D}$ roughness of the aggregate surface, the difference between the calculation results 
can be controlled below $10 \%$, and the results, therefore, exhibit a good correlation. The calculation deviation of the two roughness characterization methods was mainly caused by the differences in the test methods and data accuracy.

(4) The $3 \mathrm{D}$ profile roughness $\mathrm{JRC}^{3 \mathrm{D}}$ calculated by the characteristic parameter method can be used to quantitatively evaluate the morphological characteristics of the aggregate particle surface. It is sufficiently sensitive to describe the microlevel structure of the aggregate texture and can be used as an evaluation index of the $3 \mathrm{D}$ roughness of road aggregate surfaces.

(5) The calculation results of the $3 \mathrm{D}$ roughness of the aggregate surface are affected by the size effect. It is therefore suggested that when evaluating the surface roughness of the same batch of aggregates with the same particle size, the observation range of the analysis area should be fixed to avoid the deviation of the roughness evaluation results caused by the size effect.

\section{Data Availability}

The data used to support the findings of this study are available from the first author upon request.

\section{Conflicts of Interest}

The authors declare that they have no conflicts of interest.

\section{Acknowledgments}

The research was funded by the National Natural Science Fund (51708267).

\section{References}

[1] D. Kuang, B. Zhang, Y. Jiao, H. Chen, and L. Wang, "Impact of particle morphology on aggregate-asphalt interface behavior," Construction and Building Materials, vol. 132, pp. 142-149, 2017.

[2] I. S. Fang, T. F. CasteloBranco, J. B. Soares et al., “Aggregate shape properties and their influence on the behavior of hotmix asphalt," Journal of Materials in Civil Engineering, vol. 27, no. 7, Article ID 04014212, 2015.

[3] M. Guo and Y. Tan, "Interaction between asphalt and mineral fillers and its correlation to mastics' viscoelasticity," International Journal of Pavement Engineering, vol. 22, no. 1, pp. 1-10, 2021.

[4] M. Guo, H. Liu, Y. Jiao et al., "Effect of WMA-RAP technology on pavement performance of asphalt mixture: a state-of-theart review," Journal of Cleaner Production, vol. 266, Article ID 121704, 2020.

[5] J. Jin, Y. Gao, Y. Wu et al., "Rheological and adhesion properties of nano-organic palygorskite and linear SBS on the composite modified asphalt," Powder Technology, vol. 377, p. 212, 2021.

[6] J. Jin, Y. C. Gao, Y. R. Wu et al., "Performance evaluation of surface-organic grafting on the palygorskite nanofiber for the modification of asphalt," Construction and Building Materials, vol. 268, Article ID 121072, 2020.

[7] P. Li, J. Su, and S. Ma, "Effect of aggregate contact condition on skeleton stability in asphalt mixture," International Journal of Pavement Engineering, vol. 21, no. 2, pp. 196-202, 2020.

[8] S. Dong, E. Yenera, F. Hattatoglu, and S. Akbuluta, "Correlation between shape of aggregate and mechanical properties of asphalt concrete," Road Materials and Pavement Design, vol. 12, no. 2, pp. 239-262, 2011.

[9] Z. Hinislioglua, P. Li, X. Wu et al., "Evaluation of the contact characteristics of graded aggregate using coarse aggregate composite geometric indexes," Construction and Building Materials, vol. 247, Article ID 118608, 2020.

[10] D. Ünlüsoy and M. L. Süzen, “A new method for automated estimation of joint roughness coefficient for $2 \mathrm{D}$ surface profiles using power spectral density," International Journal of Rock Mechanics and Mining Sciences, vol. 125, Article ID 104156, 2020

[11] M. O. Idrees and B. Pradhan, "Geostructural stability assessment of cave using rock surface discontinuity extracted from terrestrial laser scanning point cloud," Journal of Rock Mechanics and Geotechnical Engineering, vol. 10, no. 3, pp. 524-544, 2018.

[12] W. J. Pan, H. S. Li, L. Y. Ling et al., "Investigation of tangential contact damping of rough surfaces from the perspective of viscous damping mechanism," ASME, 2015.

[13] M. Sharafisafa, L. Shen, and Q. Xu, "Characterisation of mechanical behaviour of 3D printed rock-like material with digital image correlation," International Journal of Rock Mechanics and Mining Sciences, vol. 112, pp. 122-138, 2018.

[14] Z. Q. Xiong, Q. Jiang, Y. H. Gong et al., "Modeling natural joint of rock mass using three dimensional scanning and printing technologies and printing technologies and its experimental verification," Rock and Soil Mechanics, vol. 36, no. 6, pp. 1566-1572, 2015.

[15] Z. R. Tang, M. Z. Liu, Y. Jiang et al., "Point cloud registration algorithm based on canonical correlation analysis," Chinese Journal of Lasers, vol. 46, no. 4, pp. 173-181, 2019.

[16] N. Babanouri, M. Asadizadeh, and Z. H. Alizade, "Modeling shear behavior of rock joints: a focus on interaction of influencing parameters," International Journal of Rock Mechanics and Mining Sciences, vol. 22, Article ID 104449, 2020.

[17] S. R. Nayak, J. Mishra, and G. Palai, "Analysing roughness of surface through fractal dimension: a review," Image and Vision Computing, vol. 89, pp. 21-34, 2019.

[18] R. Tse and D. M. Cruden, "Estimating joint roughness coefficients," International Journal of Rock Mechanics and Mining Sciences \& Geomechanics Abstracts, vol. 16, no. 5, pp. 303-307, 1979.

[19] Z. Y. Yang, S. C. Lo, and C. C. Di, "Reassessing the joint roughness coefficient (JRC) estimation using Z 2," Rock Mechanics and Rock Engineering, vol. 34, no. 3, pp. 243-251, 2001.

[20] N. Barton and V. Choubey, "The shear strength of rock joints in theory and practice," Rock Mechanics, vol. 10, no. 1-2, pp. 1-54, 1977.

[21] P. Jerónimo, R. Resende, and E. Fortunato, “An assessment of contact and laser-based scanning of rock particles for railway ballast," Transportation Geotechnics, vol. 22, Article ID 100302, 2020.

[22] K. G. Larkin, "Efficient nonlinear algorithm for envelope detection in white light interferometry," Journal of the Optical Society of America A, vol. 13, no. 4, pp. 832-843, 1996. 
[23] Z. Lei, X. Liu, L. Chen, and S. Chang, "A novel surface recovery algorithm in white light interferometry," Measurement, vol. 80, pp. 1-11, 2016.

[24] A. Lu, H. Ogawa, and K. Kitagawa, "Fast surface profiler by white-light interferometry by use of a new algorithm based on sampling theory," Applied Optics, vol. 41, no. 23, pp. 4876-4883, 2002.

[25] J. Schauer and A. Nüchter, "Removing non-static objects from 3D laser scan data," ISPRS Journal of Photogrammetry and Remote Sensing, vol. 143, pp. 15-38, 2018.

[26] Y.-H. Lee, J. R. Carr, and D. J. Barr, "The fractal dimension as a measure of the roughness of rock discontinuity profiles," International Journal of Rock Mechanics and Mining Sciences \& Geomechanics Abstracts, vol. 27, no. 6, pp. 453-464, 1990.

[27] J. Haas, "Joint surface matching and shear strength part B: JRC-JMC shear strength criterion," International Journal of Rock Mechanics and Mining Sciences, vol. 34, no. 2, pp. 179-185, 1997.

[28] A. J. Beer, D. Stead, and J. S. Coggan, "Technical note estimation of the joint roughness coefficient (JRC) by visual comparison," Rock Mechanics and Rock Engineering, vol. 35, no. 1, pp. 65-74, 2002.

[29] G. Zhang, M. Karakus, H. Tang, and L. Zhang, "A new method estimating the $2 \mathrm{D}$ joint roughness coefficient for discontinuity surfaces in rock masses," International Journal of Rock Mechanics and Mining Sciences, vol. 72, pp. 191-198, 2014.

[30] S. M. Ge, "Profilometric analysis of fractures," Metallography, vol. 11, no. 3, pp. 247-336, 2008.

[31] T. Belem, F. Homand-Etienne, and M. Souley, "Quantitative parameters for rock joint surface roughness," Rock Mechanics and Rock Engineering, vol. 33, no. 4, pp. 217-242, 2000. 